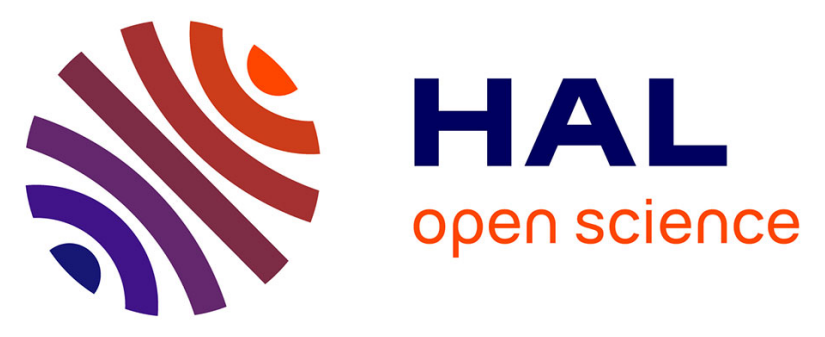

\title{
Broadband Emission in Hybrid Organic-Inorganic Halides of Group 12 Metals
}

Rachel Roccanova, Matthew Houck, Aymen Yangui, Dan Han, Hongliang Shi, Yuntao Wu, Daniel T Glatzhofer, Douglas R Powell, Shiyou Chen, Houcem Fourati, et al.

\section{To cite this version:}

Rachel Roccanova, Matthew Houck, Aymen Yangui, Dan Han, Hongliang Shi, et al.. Broadband Emission in Hybrid Organic-Inorganic Halides of Group 12 Metals. ACS Omega, 2018, 10.1021/acsomega.8b02883 . hal-02395542

\section{HAL Id: hal-02395542 \\ https://hal.science/hal-02395542}

Submitted on 5 Dec 2019

HAL is a multi-disciplinary open access archive for the deposit and dissemination of scientific research documents, whether they are published or not. The documents may come from teaching and research institutions in France or abroad, or from public or private research centers.
L'archive ouverte pluridisciplinaire HAL, est destinée au dépôt et à la diffusion de documents scientifiques de niveau recherche, publiés ou non, émanant des établissements d'enseignement et de recherche français ou étrangers, des laboratoires publics ou privés. 


\section{Broadband Emission in Hybrid Organic-Inorganic Halides of Group 12 Metals}

Rachel Roccanova, ${ }^{\dagger}$ Matthew Houck, ${ }^{\dagger}$ Aymen Yangui, ${ }^{\dagger}$ Dan Han $,{ }^{\ddagger},{ }^{\prime}, \|$ Hongliang Shi, ${ }^{\perp}$ Yuntao Wu, ${ }^{\#, \nabla}$ Daniel T. Glatzhofer, ${ }^{\dagger}$ Douglas R. Powell, ${ }^{\dagger}$ Shiyou Chen, ${ }^{\S}{ }^{\circledR}$ Houcem Fourati, ${ }^{\bigcirc}$ Alain Lusson, ${ }^{\bigcirc}$ Kamel Boukheddaden, ${ }^{\circ}$ Mao-Hua Du, ${ }^{*}, \|_{\odot}$ and Bayrammurad Saparov* ${ }^{*} \dagger$

${ }^{\dagger}$ Department of Chemistry and Biochemistry, University of Oklahoma, 101 Stephenson Parkway, Norman, Oklahoma 73019, USA

${ }^{\ddagger}$ Key Laboratory of Polar Materials and Devices (Ministry of Education) and ${ }^{\S}$ Department of Physics, East China Normal University, Shanghai 200241, China

"Materials Science and Technology Division, Oak Ridge National Laboratory, Oak Ridge, Tennessee 37831, USA

${ }^{\perp}$ Key Laboratory of Micro-Nano Measurement-Manipulation and Physics (Ministry of Education), Department of Physics, Beihang University, Beijing 100191, China

${ }^{\#}$ Scintillation Materials Research Center and ${ }^{\nabla}$ Department of Materials Science and Engineering, University of Tennessee, Knoxville, Tennessee 37996, USA

${ }^{\circ}$ Groupe d'Etudes de la Matière Condensée, UMR CNRS 8653-Université de Versailles Saint Quentin En Yvelines, Université Paris-Saclay, 45 Avenue des États-Unis, 78035 Versailles, France

\section{Supporting Information}

ABSTRACT: We report syntheses, crystal and electronic structures, and characterization of three new hybrid organic-inorganic halides (R) $\mathrm{ZnBr}_{3}(\mathrm{DMSO}),(\mathrm{R})_{2} \mathrm{CdBr}_{4}$. DMSO, and $(\mathrm{R}) \mathrm{CdI}_{3}(\mathrm{DMSO})$ (where $(\mathrm{R})=\mathrm{C}_{6}\left(\mathrm{CH}_{3}\right)_{5} \mathrm{CH}_{2} \mathrm{~N}\left(\mathrm{CH}_{3}\right)_{3}$, and DMSO = dimethyl sulfoxide). The compounds can be conveniently prepared as single crystals and bulk polycrystalline powders using a DMSO-methanol solvent system. On the basis of the single-crystal X-ray diffraction results carried out at room temperature and $100 \mathrm{~K}$, all compounds have zero-dimensional (0D) crystal structures featuring alternating layers of bulky organic cations and molecular inorganic anions based on a tetrahedral coordination around group 12 metal cations. The presence of discrete molecular building blocks in the OD structures results in localized charges and tunable room-temperature light emission, including white light for ( $\mathrm{R}) \mathrm{ZnBr}_{3}(\mathrm{DMSO})$, bluishwhite light for $(\mathrm{R})_{2} \mathrm{CdBr}_{4} \cdot \mathrm{DMSO}$, and green for (R) $\mathrm{CdI}_{3}(\mathrm{DMSO})$. The highest photoluminescence quantum yield (PLQY) value of $3.07 \%$ was measured for

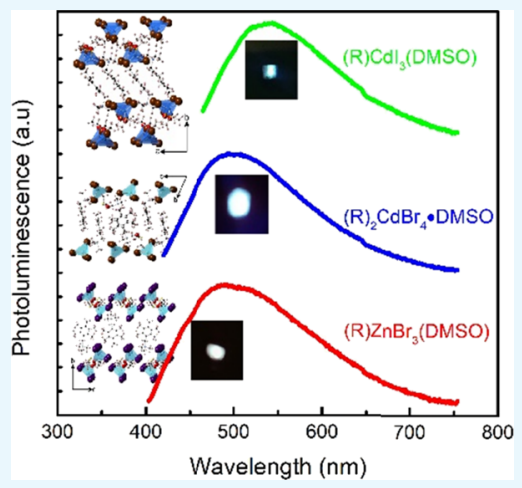
(R) $\mathrm{ZnBr}_{3}$ (DMSO), which emits cold white light based on the calculated correlated color temperature (CCT) of 11,044 K. All compounds exhibit fast photoluminescence lifetimes on the timescale of tens of nanoseconds, consistent with the fast luminescence decay observed in $\pi$-conjugated organic molecules. Temperature dependence photoluminescence study showed the appearance of additional peaks around $550 \mathrm{~nm}$, resulting from the organic salt emission. Density functional theory calculations show that the incorporation of both the low-gap aromatic molecule $\mathrm{R}$ and the relatively electropositive $\mathrm{Zn}$ and $\mathrm{Cd}$ metals can lead to exciton localization at the aromatic molecular cations, which act as luminescence centers.

\section{INTRODUCTION}

Solution-processable hybrid organic-inorganic halides have been at the forefront of optical and electronic materials research in the past decade, owing to their rich crystal chemistry and broadly tunable physical properties. ${ }^{1-6}$ Among these, $\mathrm{Pb}$ - and $\mathrm{Sn}$-based hybrid halide perovskites have been the focus of global attention because of their excellent performance in solar cells, which now have record power conversion efficiencies exceeding $22 \%{ }^{7}$ In addition, excellent light emission properties of halide perovskites have also been reported, including efficient blue emission ${ }^{8,9}$ and broadband white light emission. ${ }^{10-15}$ Inspired by these findings, further experimental studies show that nonperovskite hybrid organicinorganic halides can also have remarkable light emission properties, such as in the case of $\left(\mathrm{H}_{2} \mathrm{DABCO}\right) \mathrm{Pb}_{2} \mathrm{Cl}_{6}$ and $\left(\mathrm{H}_{3} \mathrm{O}\right)\left(\mathrm{Et}_{2}-\mathrm{DABCO}\right)_{8} \mathrm{~Pb}_{21} \mathrm{Cl}_{59}$ compounds that demonstrate white light emission with high color rendering index (CRI) values of 96 and 88 , respectively. ${ }^{16}$

The light emission properties of hybrid organic-inorganic perovskites are strongly dependent on their structural

Received: October 19, 2018

Accepted: December 13, 2018

Published: December 28, 2018 
dimensionality, with 3D perovskites behaving as typical allinorganic multinary halides with small exciton binding energies (typically below $50 \mathrm{meV}$ ). ${ }^{1,17,18}$ Conversely, low-dimensional hybrid halides demonstrate much stronger charge localization and exciton binding energies in excess of $500 \mathrm{meV}$, values that are comparable to those of tightly bound Frenkel excitons in organic materials. ${ }^{1,19}$ Such high exciton binding energies can accordingly result in room-temperature stable excitons and intense excitonic emission. Therefore, preparation and characterization of low-dimensional organic-inorganic hybrid halides for light emission applications have been the focus of several studies published in recent years. ${ }^{20-22}$

Highest charge localization and exciton binding energies are often observed in zero-dimensional (OD) compounds, ${ }^{6}$ which feature molecular inorganic anions and organic cations in their crystal structures. Indeed, numerous $\mathrm{Cu}-, \mathrm{Sn}-$, and $\mathrm{Sb}$-based OD nonperovskite hybrid halides have recently been reported to exhibit remarkable light emission properties, including photoluminescence quantum yields (PLQY) approaching unity $^{22-25}$ and large Stokes shifts above $300 \mathrm{~nm}^{26}$ The large Stokes shifts are primarily attributed to the pronounced excited-state structural distortions ${ }^{23,26}$ and, therefore, are rarely observed for materials in the solid state because of the rigidity of solid structures, which restricts significant structural reorganization. However, OD hybrid halides featuring molecular organic and inorganic units are more amenable to structural reorganization and hence exhibit broadband photoluminescence (PL) spectra with large Stokes shifts.

Unlike the $\mathrm{Pb}$ - and $\mathrm{Sn}$-based hybrid halides, the optical and electronic properties of the hybrid halides of group 12 metals remain largely unexplored. Notwithstanding a few recent publications focusing on the light emission properties of group 12 metal hybrid halides, ${ }^{19,20,27}$ most published articles focus on their intriguing structural properties, including structural dimensionalities, impact of hydrogen bonding, molecular orientations of organic cations, etc. ${ }^{28-30}$ These group 12 metal-based hybrid halides show a remarkable structural flexibility in their tunable dimensionality ${ }^{19,27}$ and incorporation of functional organic cations, such as chromophores and polymers, ${ }^{30,31}$ in $2 \mathrm{D}$ perovskite structures, both of which can be utilized to prepare functional materials for practical applications, including solid-state lighting applications. This fact is further evidenced by a recent discovery of broadband white light emission in the 2D-layered perovskite compound $\left(\mathrm{C}_{6} \mathrm{H}_{11} \mathrm{NH}_{3}\right)_{2} \mathrm{CdBr}_{4}$ originating from both organic and inorganic layers. ${ }^{20}$

In this work, we report the use of the previously reported organic trimethyl $(2,3,4,5,6$-pentamethylbenzyl)ammonium (denoted as ( $R$ ) hereafter) halides ${ }^{32}$ to prepare luminescent OD hybrid ( $\mathrm{R}$ )-M-X halides, where $\mathrm{M}=\mathrm{Zn}$ or $\mathrm{Cd}$, and $\mathrm{X}=\mathrm{Br}$ or I. Single crystals of three new compounds within the studied systems were obtained using low-temperature solution reactions. On the basis of our X-ray crystallography work, all compounds form $0 \mathrm{D}$ crystal structures featuring alternating layers of organic cations and inorganic anions that are based on tetrahedral coordination around metal cations. In (R)$\mathrm{ZnBr}_{3}$ (DMSO) and (R) $\mathrm{CdI}_{3}$ (DMSO), DMSO molecules directly coordinate to metal cations through $\mathrm{M}-\mathrm{O}$ bonds yielding $\mathrm{MX}_{3} \mathrm{DMSO}^{-}$units, whereas $(\mathrm{R})_{2} \mathrm{CdBr}_{4} \cdot \mathrm{DMSO}$ features $\mathrm{CdBr}_{4}{ }^{2-}$ anions and DMSO molecules that act as spacers in between organic and inorganic ions. No structural phase transitions are observed between room temperature and $100 \mathrm{~K}$. The optical properties were investigated using steady- state PL as a function of temperature, photoluminescence excitation (PLE), time-resolved photoluminescence (TRPL), PLQY, and density functional theory (DFT). The compounds are shown to demonstrate rare light emission from the organic component of the hybrid organic-inorganic halides, including deep blue emission and broadband white light emission with PLQY values up to $3.07 \%$.

\section{RESULTS AND DISCUSSION}

Crystal Structures. Room-temperature and low-temperature single-crystal X-ray diffraction (SXRD) experiments for hybrid bromide and iodides of $\mathrm{Zn}$ and $\mathrm{Cd}$ metals are summarized in Figure 1, Table 1, and Tables S1-S3. On the

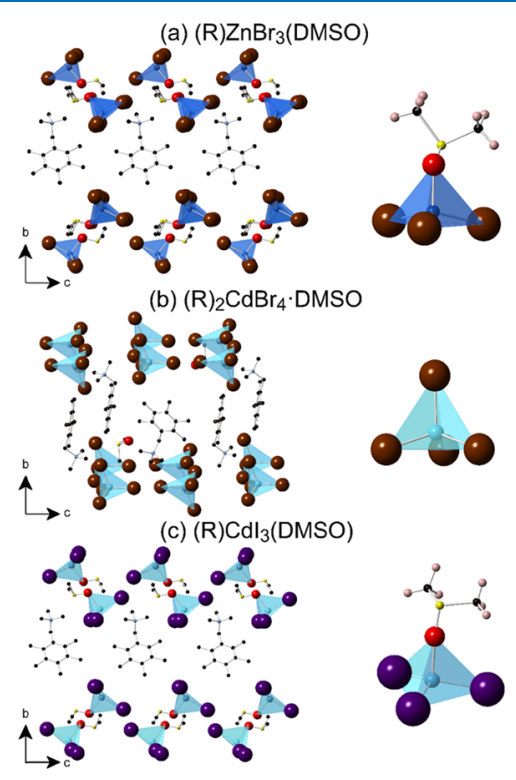

Figure 1. $(\mathrm{a}-\mathrm{c})$ Crystal structures and close-up views of the coordination polyhedra in (a) (R) $\mathrm{ZnBr}_{3}(\mathrm{DMSO})$, (b) (R) ${ }_{2} \mathrm{CdBr}_{4}$. DMSO, and (c) (R) $\mathrm{CdI}_{3}(\mathrm{DMSO})$. Blue and cyan tetrahedra represent coordination environments around $\mathrm{Zn}$ and $\mathrm{Cd}$, respectively. Burgundy, purple, red, yellow, black, and light blue spheres represent $\mathrm{Br}, \mathrm{I}, \mathrm{O}, \mathrm{S}, \mathrm{C}$, and $\mathrm{N}$, respectively. For clarity, hydrogen atoms were omitted, and only a fraction of organic cations and solvent molecules are shown.

basis of the obtained results, there are no structural transitions between room temperature and $100 \mathrm{~K}$ for all reported compounds; instead, normal contraction of the unit cell volume is observed upon cooling (Table 1 and Table S1). As expected, the use of bulky nonlinear organic cation results in OD crystal structures for (R) $\mathrm{ZnBr}_{3}(\mathrm{DMSO}),(\mathrm{R})_{2} \mathrm{CdBr}_{4}$. DMSO, and $(\mathrm{R}) \mathrm{CdI}_{3}(\mathrm{DMSO})$ featuring alternating layers of isolated inorganic anions and organic cations. In all cases, DMSO solvent molecules are incorporated into the crystal structures of the resultant compounds. In the case of ( $\mathrm{R})_{2} \mathrm{CdBr}_{4} \cdot \mathrm{DMSO}$, the coordination environment around $\mathrm{Cd}^{2+}$ only consists of bromide anions yielding $\mathrm{CdBr}_{4}{ }^{2-}$ anions and DMSO molecules acting as spacers in between organic and inorganic ions. However, in ( $\mathrm{R}) \mathrm{ZnBr}_{3}$ (DMSO) and (R)$\mathrm{CdI}_{3}$ (DMSO), DMSO molecules and halide anions form the coordination environment around metal cations through direct $\mathrm{M}-\mathrm{O}$ bonds yielding $\mathrm{MX}_{3} \mathrm{DMSO}^{-}$units (Figure 1). Notice that the formula for $(\mathrm{R})_{2} \mathrm{CdBr}_{4} \cdot \mathrm{DMSO}$ is written differently compared to (R) $\mathrm{ZnBr}_{3}(\mathrm{DMSO})$ and $(\mathrm{R}) \mathrm{CdI}_{3}(\mathrm{DMSO})$ to emphasize the direct coordination of DMSO molecules to the 
Table 1. Selected Room-Temperature Single-Crystal Data Collection and Refinement Parameters for the Compounds Prepared in This Work

\begin{tabular}{|c|c|c|c|}
\hline formula & (R) $\mathrm{ZnBr}_{3}(\mathrm{DMSO})$ & $(\mathrm{R})_{2} \mathrm{CdBr} 4 \cdot \mathrm{DMSO}$ & (R) $\mathrm{CdI}_{3}(\mathrm{DMSO})$ \\
\hline formula weight $(\mathrm{g} / \mathrm{mol})$ & 603.59 & 950.90 & 791.59 \\
\hline temperature $(\mathrm{K})$ & $298(2)$ & $298(2)$ & $298(2)$ \\
\hline radiation, wavelength $(\AA)$ & Mo $\mathrm{K} \alpha, 0.71073$ & Mo $\mathrm{K} \alpha, 0.71073$ & Mo $\mathrm{K} \alpha, 0.71073$ \\
\hline crystal system & orthorhombic & triclinic & orthorhombic \\
\hline space group, $Z$ & $P 2_{1} 2_{1} 2,4$ & $P-1,2$ & $P 2_{1} 2,2,4$ \\
\hline$a(\AA)$ & $9.116(2)$ & $8.9894(6)$ & $9.3959(6)$ \\
\hline$b(\AA)$ & $28.767(7)$ & $14.3500(9)$ & $29.5322(19)$ \\
\hline$c(\AA)$ & $8.892(2)$ & $15.9925(10)$ & $9.3829(6)$ \\
\hline$\alpha,{ }^{\circ}$ & 90 & $72.1342(11)$ & 90 \\
\hline$\beta, \circ$ & 90 & $89.0598(12)$ & 90 \\
\hline$\gamma,{ }^{\circ}$ & 90 & $89.2993(11)$ & 90 \\
\hline volume $\left(\AA^{3}\right)$ & $2331.8(10)$ & 1963.1(2) & 2603.6(3) \\
\hline $\operatorname{density~}\left(\rho_{\text {calc }}\right)\left(\mathrm{g} / \mathrm{cm}^{3}\right)$ & 1.719 & 1.609 & 2.019 \\
\hline absorption coefficient $(\mu)\left(\mathrm{mm}^{-1}\right)$ & 6.289 & 4.706 & 4.481 \\
\hline$\theta_{\min }-\theta_{\max }\left({ }^{\circ}\right)$ & $2.29-26.41$ & $1.34-25.70$ & $1.38-29.67$ \\
\hline reflections collected & 34552 & 44472 & 66620 \\
\hline independent reflections & 4544 & 7464 & 7362 \\
\hline$R^{a}$ indices $(I>2 \sigma(I))$ & $R_{1}=0.0398, w R_{2}=0.0892$ & $R_{1}=0.0324, w R_{2}=0.0690$ & $R_{1}=0.0370, w R_{2}=0.0977$ \\
\hline goodness-of-fit on $F^{2}$ & 0.918 & 1.008 & 1.013 \\
\hline largest diff. peak and hole $\left(\mathrm{e}^{-} / \AA^{3}\right)$ & 0.626 and -0.739 & 0.816 and -0.626 & 1.320 and -0.926 \\
\hline
\end{tabular}
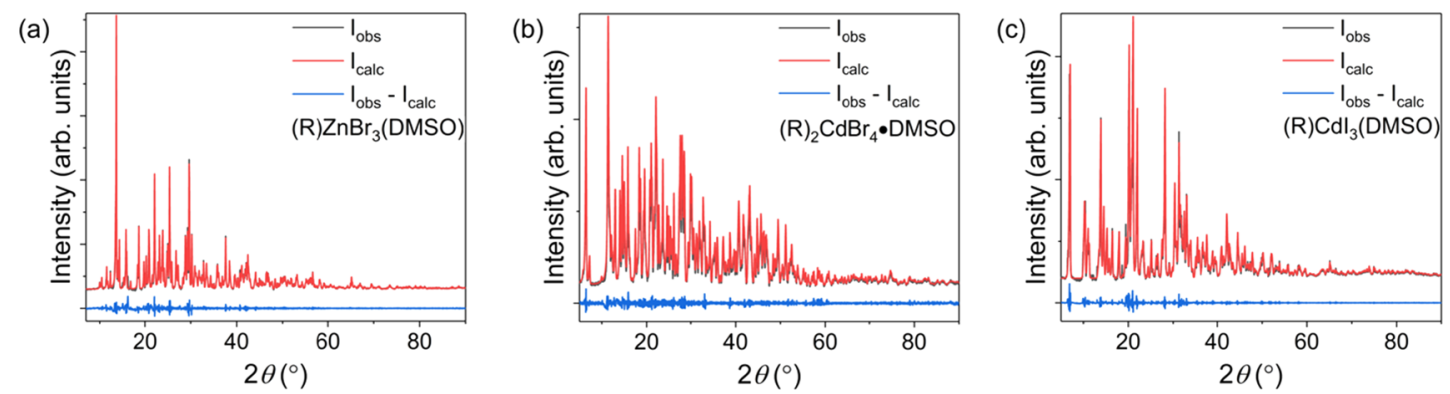

Figure 2. (a-c) PXRD patterns (black lines) for (a) (R) $\mathrm{ZnBr}_{3}(\mathrm{DMSO}),(\mathrm{b})(\mathrm{R})_{2} \mathrm{CdBr}_{4} \cdot \mathrm{DMSO}$, and (c) (R)CdI ${ }_{3}(\mathrm{DMSO})$. The Pawley fits and difference plots are shown as red and blue curves, respectively.

metals in the latter. The measured $\mathrm{M}-\mathrm{O}$ bond distances of $d_{\mathrm{Zn}-\mathrm{O}}=2.024(5) \AA$ and $d_{\mathrm{Cd}-\mathrm{O}}=2.247(7) \AA$ in $(\mathrm{R})$ $\mathrm{ZnBr}_{3}(\mathrm{DMSO})$ and (R) $\mathrm{CdI}_{3}(\mathrm{DMSO})$ (Table S2), respectively, follow the expected trend based on the sizes of $\mathrm{Zn}^{2+}$ and $\mathrm{Cd}^{2+}$ ions. ${ }^{33}$ These values are slightly longer than the literaturereported $\mathrm{Zn}-\mathrm{O}$ and $\mathrm{Cd}-\mathrm{O}$ bond distances in oxyhalides such as $\mathrm{Zn}_{0.902} \mathrm{SbBrO}_{2}\left(d_{\mathrm{Zn}-\mathrm{O}}=1.897 \AA\right)$ and $\mathrm{BiCdIO}_{2}\left(d_{\mathrm{Cd} / \mathrm{Bi}-\mathrm{O}}=\right.$ $2.239 \AA) .{ }^{34}$ On the other hand, the metal halide bond distances are in the $d_{\mathrm{Zn}-\mathrm{Br}}=2.38-2.40 \AA$ range for $(\mathrm{R}) \mathrm{ZnBr}_{3}(\mathrm{DMSO})$, $d_{\mathrm{Cd}-\mathrm{Br}}=2.58-2.61 \AA$ for $(\mathrm{R})_{2} \mathrm{CdBr}_{4} \cdot \mathrm{DMSO}$, and $d_{\mathrm{Cd}-\mathrm{I}}=$ 2.72-2.73 $\AA$ for (R) $\mathrm{CdI}_{3}(\mathrm{DMSO})$. These values compare well with those reported for other hybrid organic-inorganic halides of $\mathrm{Zn}$ and $\mathrm{Cd}$, including $\left[4,4^{\prime}-\mathrm{H}_{2}\right.$ bipy] $\left[\mathrm{ZnBr}_{4}\right]\left(d_{\mathrm{Zn}-\mathrm{Br}}=2.39-\right.$ $2.43 \AA),{ }^{29}\left(\mathrm{CH}_{3} \mathrm{NH}_{3}\right)_{2} \mathrm{CdBr}_{4}\left(d_{\mathrm{Cd}-\mathrm{Br}}=2.57-2.59 \AA\right)$, and $\left(\mathrm{CH}_{3} \mathrm{NH}_{3}\right)_{2} \mathrm{CdI}_{4}\left(d_{\mathrm{Cd}-\mathrm{I}}=2.72-2.75 \AA\right) .{ }^{19}$ In all compounds, the tetrahedral coordination around the metal cations are distorted, with bond angles ranging from $98.97(19)^{\circ}$ to $118.37(3)^{\circ}$ in $(\mathrm{R}) \mathrm{CdI}_{3}(\mathrm{DMSO})$ (Table S2). It should be noted that the presence of DMSO in the coordination sphere of $\mathrm{Cd}^{2+}$ undoubtedly contributes to the observed distortion in (R) $\mathrm{CdI}_{3}$ (DMSO); however, tetrahedral distortions are also observed for cadmium halides with no coordinating solvent molecules including $(\mathrm{R})_{2} \mathrm{CdBr}_{4} \cdot \mathrm{DMSO}$, which features $\mathrm{CdBr}_{4}{ }^{2-}$ units, and in literature, for $\left(\mathrm{CH}_{3} \mathrm{NH}_{3}\right)_{2} \mathrm{CdBr}_{4}$ and $\left(\mathrm{CH}_{3} \mathrm{NH}_{3}\right)_{2} \mathrm{CdI}_{4} \cdot{ }^{19}$

Stability Studies. On the basis of the results of our powder X-ray diffraction (PXRD) measurements, all compounds form phase-pure products (Figure 2). The PXRD patterns in all cases have several characteristic low angle peaks, indicative of large unit cell parameters stemming from the use of the bulky organic cation. Poor stability in air is an often-cited deficiency of some of the most well-known hybrid organic-inorganic halides, including the state-of-the-art photovoltaic material $\mathrm{CH}_{3} \mathrm{NH}_{3} \mathrm{PbI}_{3}$. $^{35,36}$ To test the air stability of our compounds, powdered samples were allowed to sit undisturbed under ambient conditions over a period of 1 month. Periodic PXRD scans taken on the samples exposed to ambient air (Figure S5) indicate that all samples are stable for at least several days. Noticeable changes are recorded for $(\mathrm{R}) \mathrm{CdI}_{3}(\mathrm{DMSO})$, which shows lowered peak intensities and peak broadening after 2 weeks (Figure S5), indicative of reduced crystallinity. These results are consistent with the trend we recently observed for the $\left(\mathrm{CH}_{3} \mathrm{NH}_{3}\right)_{2} \mathrm{CdX}_{4}(\mathrm{X}=\mathrm{Cl}, \mathrm{Br}$, or I $)$ series, in which air stability is markedly worse for the iodide compared to the 
(a)

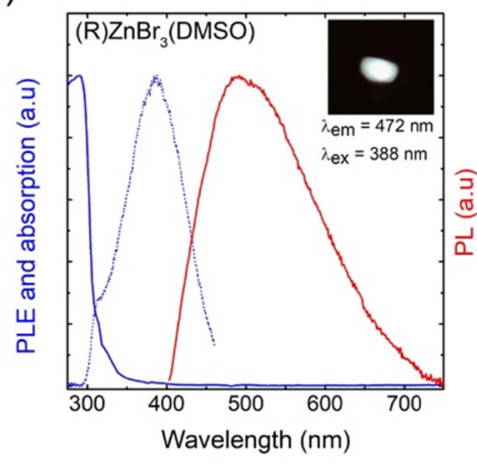

(c)

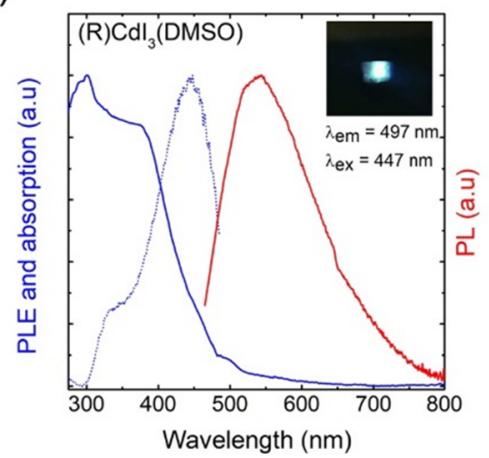

(b)

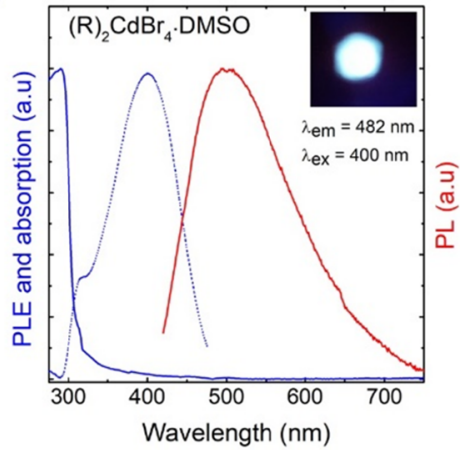

(d)

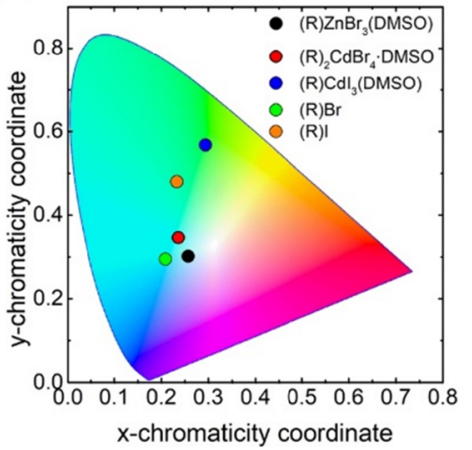

Figure 3. (a-c) Room-temperature optical absorption (blue solid lines), PLE (blue dotted lines), and PL (red solid lines) spectra for the compounds studied in this work. The insets show the bright emission from the powder samples under irradiation with their respective maximum excitation wavelengths. (d) CIE 1931 chromaticity diagram showing the emission colors of the compounds and the organic salts.

Table 2. Summary of the Optical Properties of the Organic-Inorganic Hybrid Compounds $(R) \mathrm{ZnBr}_{3}(\mathrm{DMSO}),(\mathrm{R}){ }_{2} \mathrm{CdBr}{ }_{4}{ }^{\circ}$ DMSO, and (R) $\mathrm{CdI}_{3}(\mathrm{DMSO})$ and the Corresponding Organic Salts (R)Br and (R)I

\begin{tabular}{|c|c|c|c|c|c|c|c|}
\hline compound & PLQY (\%) & FWHM (nm) & $\operatorname{PLE}_{\max }(\mathbf{n m})$ & $\mathbf{P L}_{\max }(\mathbf{n m})$ & Stokes shift (nm) & \multicolumn{2}{|c|}{ CIE coordinates } \\
\hline (R) $\mathrm{ZnBr}_{3}(\mathrm{DMSO})$ & 3.07 & 188 & 386 & 491 & 105 & 0.26 & 0.30 \\
\hline$(\mathrm{R})_{2} \mathrm{CdBr}_{4} \cdot \mathrm{DMSO}$ & 0.32 & 164 & 399 & 501 & 102 & 0.24 & 0.35 \\
\hline (R) $\mathrm{CdI}_{3}(\mathrm{DMSO})$ & 0.27 & 162 & 445 & 515 & 70 & 0.29 & 0.57 \\
\hline$(\mathrm{R}) \mathrm{Br}$ & 2.44 & 153 & 378 & 462 & 84 & 0.21 & 0.29 \\
\hline$(\mathrm{R}) \mathrm{I}$ & 0.42 & 168 & 416 & 514 & 98 & 0.23 & 0.48 \\
\hline
\end{tabular}
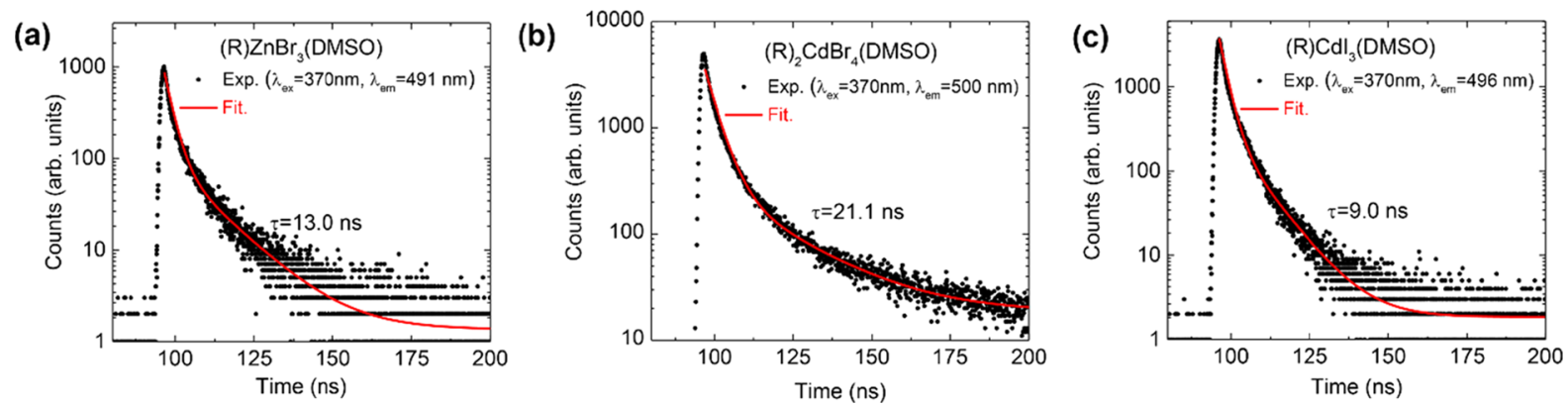

Figure 4. $(\mathrm{a}-\mathrm{c})$ Photoluminescence lifetime profiles (black solid circles) and fitting curves (red lines) for $(\mathrm{a})(\mathrm{R}) \mathrm{ZnBr}_{3}(\mathrm{DMSO}),(\mathrm{b})(\mathrm{R})_{2} \mathrm{CdBr}{ }_{4}$. DMSO, and $(\mathrm{c})(\mathrm{R}) \mathrm{CdBr}_{3}(\mathrm{DMSO})$. The insets show the excitation and emission wavelengths and the derived lifetime constants.

chloride analogue. ${ }^{19}$ Furthermore, extensive studies on halide perovskites also suggest reduced air stabilities going from chlorides to iodides.

Optical Properties. The highly tunable light emission properties in this series studied through room-temperature optical absorption, PL, and PLE measurements are summarized in Figure 3 and Table 2. Optical absorption spectra show a sharp absorption peak at $\sim 290 \mathrm{~nm}$, accompanied with a shoulder at 315,320 , and $360 \mathrm{~nm}$ for (R) $\mathrm{ZnBr}_{3}(\mathrm{DMSO})$, (R) ${ }_{2} \mathrm{CdBr}_{4} \cdot \mathrm{DMSO}$, and (R) $\mathrm{CdI}_{3}(\mathrm{DMSO})$, respectively. These optical absorption bands were attributed to the organic molecule. Moreover, PLE spectra show the presence of a sharp peak at 386, 399, and $445 \mathrm{~nm}$ for (R) $\mathrm{ZnBr}_{3}$ (DMSO), $(\mathrm{R})_{2} \mathrm{CdBr}_{4} \cdot \mathrm{DMSO}$, and (R) $\mathrm{CdI}_{3}(\mathrm{DMSO})$, respectively. These peaks were assigned to the excitonic absorption. ${ }^{37}$ Similar to the earlier reports on $\mathrm{Cd}$ - and $\mathrm{Pb}$-based hybrid halide 
perovskites, ${ }^{12,19-21,38-40}$ all compounds studied in this work exhibit broadband emission spectra with full width at half maximum (FWHM) values ranging from $162 \mathrm{~nm}$ for (R) $\mathrm{CdI}_{3}(\mathrm{DMSO})$ to $188 \mathrm{~nm}$ for (R) $\mathrm{ZnBr}_{3}(\mathrm{DMSO})$. Importantly, bright broadband white light emission is observed for (R) $\mathrm{ZnBr}_{3}$ (DMSO). The corresponding Commission Internationale de l'Eclairage (CIE) color coordinates $(x, y)$ of $(0.26,0.30)$ for $(\mathrm{R}) \mathrm{ZnBr}_{3}$ (DMSO) are close to the white point $(0.33,0.33)$ coordinates. $(\mathrm{R})_{2} \mathrm{CdBr}_{4} \cdot \mathrm{DMSO}$ emits bluish-white light with CIE coordinates of $(0.24,0.35)$, whereas $(\mathrm{R}) \mathrm{CdI}_{3}(\mathrm{DMSO})$ emits green light $(0.29,0.57)$. For the compounds with emission on the Planckian locus, the calculated correlated color temperatures (CCT) using the approach proposed by Hernández-Andrés et al. ${ }^{41}$ are $11044 \mathrm{~K}$ for (R) $\mathrm{ZnBr}_{3}$ (DMSO) and $10384 \mathrm{~K}$ for $(\mathrm{R})_{2} \mathrm{CdBr}_{4} \cdot \mathrm{DMSO}^{41}$ Such high values suggest that these compounds emit "cool" bluish-white and white colors similar to the cold white lightemitting Pb-based halide perovskites. ${ }^{39}$

The room-temperature PL lifetime profiles of the compounds prepared in this work are plotted in Figure 4. All the profiles monitoring the emission at the wavelength of maximum intensity can be well fitted by two-exponential functions. The first lifetime component of 1-2 ns for all compounds is due to the instrumental response because of the duration of the light pulse ( $2 \mathrm{~ns})$. The measured PL lifetimes of these compounds range from 9 to 21.1 ns (Figure 4). In the literature, a spread in PL lifetimes of Pb-based hybrid halides is reportedly ranging from subnanoseconds up to $54.1 \mathrm{~ns},{ }^{16,21,39}$ attributed to self-trapped excitonic states (STEs), and for some OD Pb-free hybrid halides, phosphorescence lifetimes in microseconds are reported. ${ }^{23,26,42}$

In hybrid metal halide perovskites, tunable broadband emission has been attributed to structural distortions, particularly to the distortions of the inorganic $\mathrm{MX}_{6}$ octahedra. $^{12,20,43}$ According to these studies, structural distortions directly impact band gaps and the spread in the structural distortions, therefore broadening the emission spectra. Although the compounds studied in this work are not perovskites and are not based on octahedral inorganic frameworks, tetrahedral distortions around metal cations are clearly evident for each compound (Table S2). However, in the present case, we cannot establish a clear correlation between tetrahedral distortions and the measured FWHM values because of the differing crystal structures and coordination environments around the metal cations in this family. Nevertheless, the structural distortions observed in our compounds could, in principle, aid in the generation of more transient photoexcited STEs similar to those in $\mathrm{Pb}$ halide perovskites. $^{39,44,45}$ For OD hybrid halides of $\mathrm{Sn}$ and $\mathrm{Sb}$, it has been shown that the significant structural distortions of the excited state also lead to large Stokes shifts of 200-350 $\mathrm{nm} .^{23,26}$ Although we observe smaller Stokes shifts ranging from $70 \mathrm{~nm}$ for (R) $\mathrm{CdI}_{3}$ (DMSO) to $105 \mathrm{~nm}$ for (R)$\mathrm{ZnBr}_{3}$ (DMSO), these values are still much higher than those for higher dimensional (2D and 3D) hybrid halide perovskites. ${ }^{46}$ The impact of distortions of the inorganic anions would be greatest if light emission originates from the inorganic molecules, that is, if the excitons are localized on the inorganic units. Unlike the heavily studied $\mathrm{Sn}$ and $\mathrm{Pb}$ halide systems, in the present case, we employed group 12 metals ( $\mathrm{Zn}$ and $\mathrm{Cd}$ ), which have lower electronegativities ${ }^{47}$ and, hence, higher lying conduction bands for the inorganic anions. Consequently, excitons in (R) $\mathrm{ZnBr}_{3}(\mathrm{DMSO})$,
(R) ${ }_{2} \mathrm{CdBr}_{4} \cdot \mathrm{DMSO}$, and (R) $\mathrm{CdI}_{3}$ (DMSO) could be localized on the organic molecules, and the relatively smaller Stokes shifts in our compounds (between 70 and $105 \mathrm{~nm}$ ) could be a direct consequence of this fact. Recently, broadband white light emission in the 2D-layered perovskite compound $\left(\mathrm{C}_{6} \mathrm{H}_{11} \mathrm{NH}_{3}\right)_{2} \mathrm{CdBr}_{4}$ was reported and attributed to both organic and inorganic layers emissions. ${ }^{20}$ Another recent report of yellowish-white light emission in the $1 \mathrm{D}$ hybrid perovskite $\left(\mathrm{C}_{9} \mathrm{H}_{10} \mathrm{~N}_{2}\right) \mathrm{PbCl}_{4}$ attributed its emission properties to a resonant energy transfer mechanism from the inorganic $\mathrm{PbCl}_{4}$ to the organic molecules. ${ }^{40}$ To further study the origin of the broadband light emission in our compounds, we have also carried out PL and PLE measurements on the precursor organic salts $(\mathrm{R}) \mathrm{Br}$ and $(\mathrm{R}) \mathrm{I}$, which are provided in Figure 5.
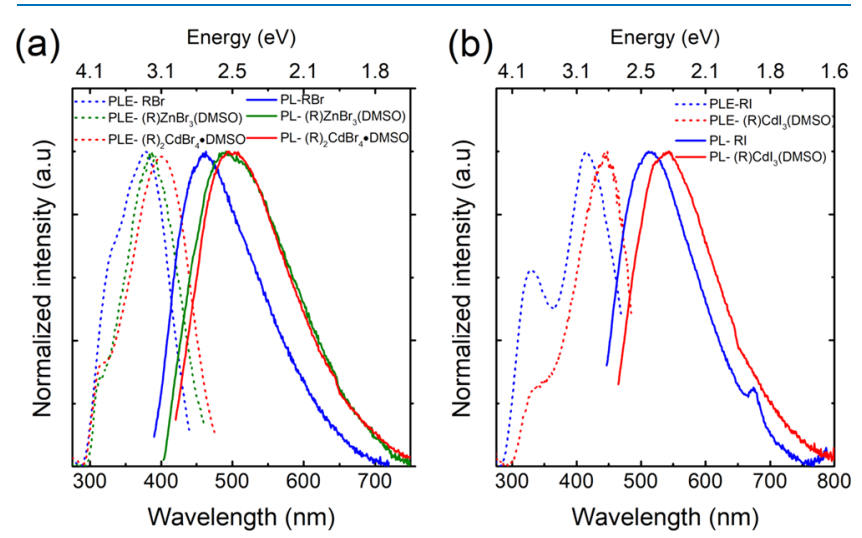

Figure 5. ( $a, b$ ) Room-temperature PLE (dashed lines) and PL spectra (solid lines) of the (a) (R)Br organic salt and (R)Br-based compounds and (b) (R)I organic salt and (R)I-based compound. Spectra are normalized for clarity.

The corresponding binary inorganic halides do not luminesce at room temperature because of thermal quenching effects. $^{19,42,48-51}$ As shown in Table 2, (R)Br emits a light blue color with CIE coordinates of $(0.21,0.29)$, whereas $(R) I$ emits a light green color with CIE coordinates of $(0.23,0.48)$. Importantly, the $\mathrm{PL}$ and PLE spectra of (R) $\mathrm{ZnBr}_{3}$ (DMSO), $(\mathrm{R})_{2} \mathrm{CdBr}_{4} \cdot \mathrm{DMSO}$, and (R) $\mathrm{CdI}_{3}(\mathrm{DMSO})$ are largely similar to that of $(\mathrm{R}) \mathrm{Br}$ and $(\mathrm{R}) \mathrm{I}$ (Figure 5 ), suggesting that the emission in our hybrid halides originates from the organic molecules. The red shift of the PL peaks of the hybrid halides compared to the organic salts can be attributed to the difference in the crystal structures of the precursor organic salts and hybrid halides and the resultant higher charge localization in hybrid halides.

The measured room-temperature PLQY values range from $0.27 \%$ for $(\mathrm{R}) \mathrm{CdI}_{3}(\mathrm{DMSO})$ to $3.07 \%$ for $(\mathrm{R}) \mathrm{ZnBr}_{3}$ (DMSO), which are comparable or higher than most of the reported broadband light emitters based on lead halide perovskites. ${ }^{10,21,52,53}$ The precursor salts (R)Br and (R)I demonstrate PLQY values of 2.44 and $0.42 \%$, respectively. Therefore, the emission efficiency is increased upon incorporation of the organic molecule into ( $\mathrm{R}) \mathrm{ZnBr}_{3}$ (DMSO) but is decreased in $(\mathrm{R})_{2} \mathrm{CdBr}_{4} \cdot \mathrm{DMSO}$ and $(\mathrm{R}) \mathrm{CdI}_{3}$ (DMSO). A direct comparison with PLQY values for other hybrid halides of group 12 metals cannot be made because of the apparent lack of indepth investigations of their light emission properties. However, our recent study on $\left(\mathrm{CH}_{3} \mathrm{NH}_{3}\right)_{2} \mathrm{CdX}_{4}(\mathrm{X}=\mathrm{Cl}, \mathrm{Br}$, or $\mathrm{I})^{19}$ reports that these compounds do not luminesce at room temperature, which seems to confirm the validity of the 

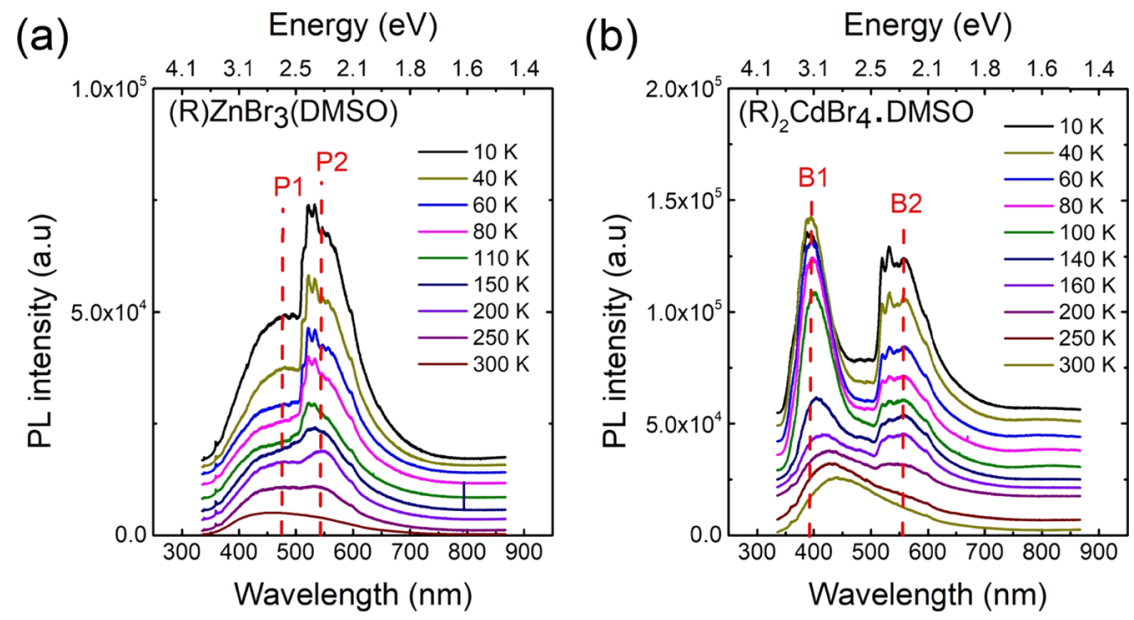

Figure 6. (a, b) Temperature dependence of $\mathrm{PL}$ spectra measured for (a) (R) $\mathrm{ZnBr}_{3}(\mathrm{DMSO})$ and $(\mathrm{b})(\mathrm{R})_{2} \mathrm{CdBr}_{4} \mathrm{DMSO}$ under $325 \mathrm{~nm}$ irradiation.

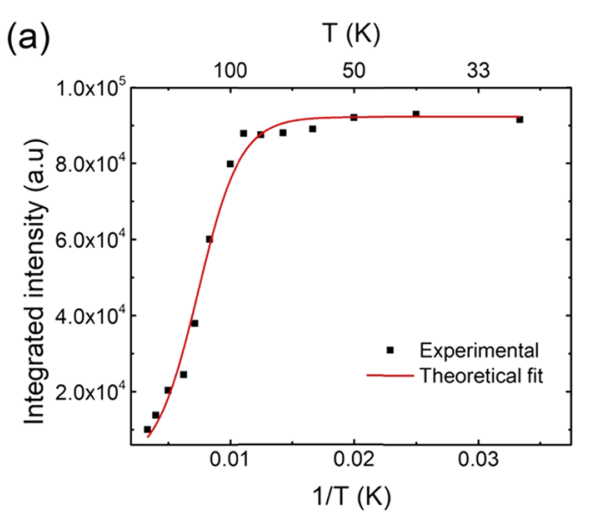

(b)

(c)
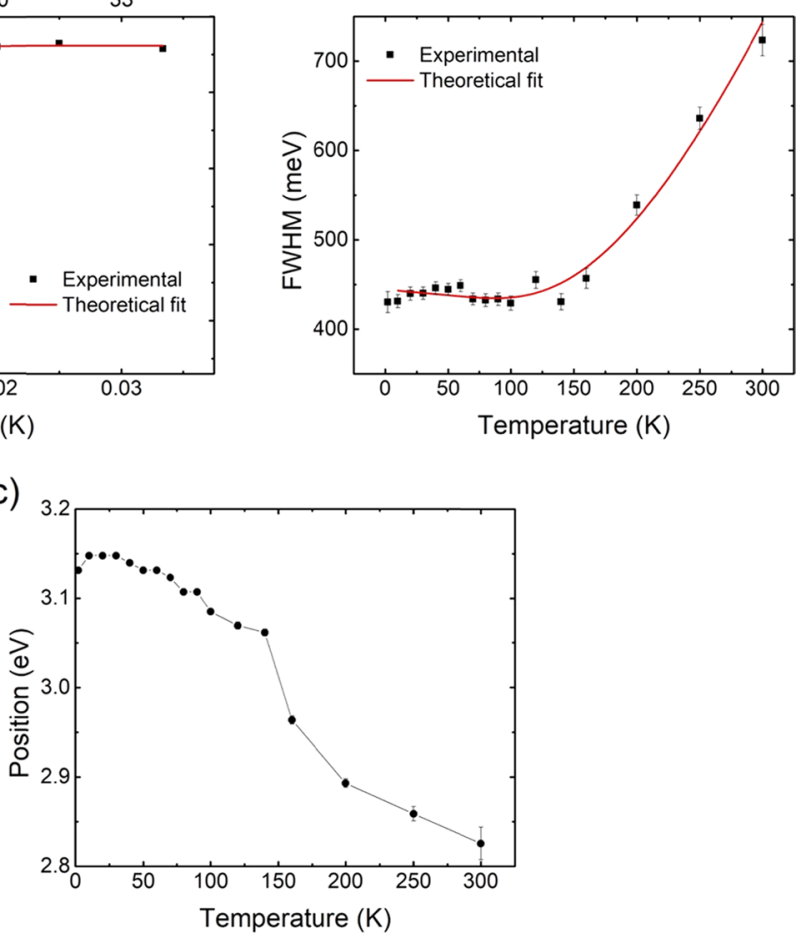

Figure 7. $(\mathrm{a}-\mathrm{c})$ Temperature dependence of $(\mathrm{a})$ the integrated intensity, (b) FWHM, and (c) the position of B1 peak of $(\mathrm{R})_{2} \mathrm{CdBr}{ }_{4} \cdot \mathrm{DMSO}$ deduced from the PL spectra shown in Figure 6. The red lines in (a) and (b) are the best fit of the experimental data according to eqs 1 and 2, respectively.

strategy of using bulky luminescent organic cations to create OD structures with molecular organic and inorganic ions to prepare room-temperature luminescent hybrid halides, as employed in this work.

To get further information about the thermally activated processes and the origin of the broadband emission, we measured the temperature dependence PL spectra for two of the more stable compounds in this family, (R) $\mathrm{ZnBr}_{3}(\mathrm{DMSO})$ and $(\mathrm{R})_{2} \mathrm{CdBr}_{4} \cdot \mathrm{DMSO}$, under a $325 \mathrm{~nm}$ laser excitation (Figure 6a,b). Significant temperature-dependent changes were revealed. For both $\mathrm{Zn}$ - and Cd-based compounds, the room temperature PL spectrum shows the presence of only one broadband, denoted as $\mathrm{P} 1$ and $\mathrm{B} 1$ in Figure $6 \mathrm{a}, \mathrm{b}$ for (R) $\mathrm{ZnBr}_{3}(\mathrm{DMSO})$ and $(\mathrm{R})_{2} \mathrm{CdBr}_{4} \cdot \mathrm{DMSO}$, respectively.
Upon cooling, additional PL peaks (denoted as P2 for (R) $\mathrm{ZnBr}_{3}$ (DMSO) and $\mathrm{B} 2$ for $(\mathrm{R})_{2} \mathrm{CdBr}_{4}$.DMSO) emerge at around $550 \mathrm{~nm}$. These peaks split into multiple sub-bands below $200 \mathrm{~K}$. The splitting of PL peaks is often observed in organic-inorganic hybrid materials and may originate from the presence of free and bi-excitons, ${ }^{54}$ free exciton and excitonphonon interactions, ${ }^{55}$ or free and bound excitons ${ }^{5}$ or could even result from the presence of structural phase transitions often observed in these hybrid materials. The latter possibility is ruled out in the present case by our room-temperature and $100 \mathrm{~K}$ SXRD measurements, suggesting the absence of structural phase transitions in the $100-300 \mathrm{~K}$ range. ${ }^{56-58}$ In the present case, very similar thermal behavior was observed for (R) $\mathrm{ZnBr}_{3}(\mathrm{DMSO})$ and for $(\mathrm{R})_{2} \mathrm{CdBr}_{4} \cdot \mathrm{DMSO}$, which 

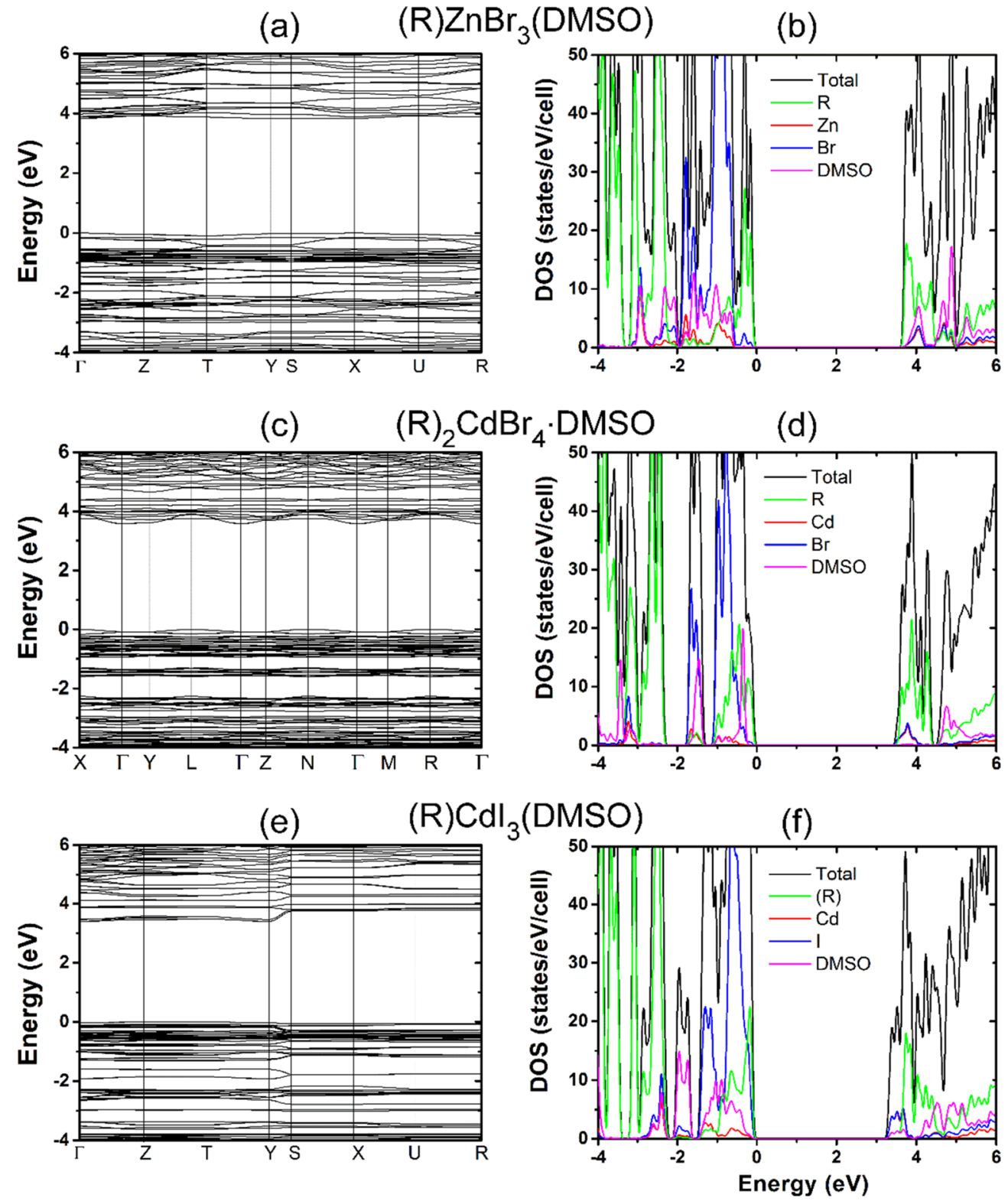

Figure 8. $(a-f)$ Band structures and DOS plots for $(a, b)(R) \mathrm{ZnBr}_{3}(\mathrm{DMSO}),(\mathrm{c}, \mathrm{d})(\mathrm{R})_{2} \mathrm{CdBr}_{4} \cdot \mathrm{DMSO}$, and $(\mathrm{e}, \mathrm{f})(\mathrm{R}) \mathrm{CdI}{ }_{3}(\mathrm{DMSO})$.

suggests that the appearance of additional low-temperature PL peaks could result from the emission of the organic cation. On the basis of the temperature dependence PL data shown in Figure $6 \mathrm{~b}$, we plotted the thermal dependence of the integrated intensity, the FWHM, and the position of B1 PL band of $(\mathrm{R})_{2} \mathrm{CdBr}_{4} \cdot \mathrm{DMSO}$ in Figure 7 . The quenching of the B1 peak could be described by the following Arrhenius-type model ${ }^{55}$

$$
I_{\mathrm{PL}}=\frac{I_{0}}{1+a \exp \left(\frac{-E_{\mathrm{a}}}{k_{\mathrm{B}} T}\right)}
$$

where $I_{0}$ is the low-temperature $\mathrm{PL}$ intensity, $k_{\mathrm{B}}$ is the Boltzmann constant, $T$ is the temperature, $a$ is the ratio between the radiative and the nonradiative decay rates, and $E_{\mathrm{a}}$ is the activation energy. The best fit of the experimental data presented in Figure 7a yields $I_{0}=9.2 \times 10^{4} \pm 830, a=76 \pm 8$, and $E_{\mathrm{a}}=48 \pm 4 \mathrm{meV}$. This activation energy presents a good agreement with those reported in similar organic-inorganic hybrid materials such as $\left(\mathrm{C}_{6} \mathrm{H}_{11} \mathrm{NH}_{3}\right)_{2} \mathrm{PbBr}_{4}{ }^{12}$ and
$\left(\mathrm{C}_{6} \mathrm{H}_{11} \mathrm{NH}_{3}\right)_{2} \mathrm{CdBr}_{4}{ }^{20}$ Moreover, the remarkable broadening of B1 PL peak as a function of temperature (Figure $7 \mathrm{~b}$ ) can be attributed to exciton-phonon interaction described within the following law ${ }^{59}$

$$
\Gamma(T)=\Gamma_{0}+\Gamma_{\mathrm{AC}} \times T+\frac{\Gamma_{\mathrm{LO}}}{\exp \left(\frac{E_{\mathrm{LO}}}{k_{\mathrm{B}} T}\right)-1}
$$

where the first term represents the natural line width at $0 \mathrm{~K}$, the second term is the broadening induced by acoustic phonons, and the third term corresponds to the contribution of optical phonons to the peak broadening. The best fit parameters yield $\Gamma_{0}=440 \pm 38 \mathrm{meV}, \Gamma_{\mathrm{AC}}=0.76 \pm 0.03 \mathrm{meV}$ $\mathrm{K}^{-1}, \Gamma_{\mathrm{LO}}=22 \pm 4 \mathrm{meV}$, and $E_{\mathrm{LO}}=16 \pm 2 \mathrm{meV}$. Once again, these values are in good agreement with those reported in organic-inorganic hybrid materials such as $\left(\mathrm{C}_{6} \mathrm{H}_{11} \mathrm{NH}_{3}\right)_{2} \mathrm{CdBr}_{4}{ }^{20}$ and those of the inorganic perovskite $\mathrm{CsCdBr}_{3}{ }^{60}$ and $\mathrm{CdBr}_{2}$ crystals. ${ }^{61}$ On the other hand, the B1 PL peak of $(\mathrm{R})_{2} \mathrm{CdBr}_{4} \cdot \mathrm{DMSO}$ shows a continuous red shift as a 
function of temperature (Figure 7c), which is usually the case for excitonic PL peaks accompanied with a clear regime change around $150 \mathrm{~K}$. This is attributed to the impact of the appearance of the B2 PL peak at low temperature, which may cause a competition in the recombination process between $\mathrm{B} 1$ and B2 PL bands.

First-Principle Calculations. Electronic band structure calculations were performed to further investigate the optical properties of the compounds prepared in this work. Figure 8 displays the electronic band structures and DOS plots for (R) $\mathrm{ZnBr}_{3}$ (DMSO), (R) ${ }_{2} \mathrm{CdBr}_{4} \cdot \mathrm{DMSO}$, and (R)$\mathrm{CdI}_{3}$ (DMSO), which show the PBE-calculated band gaps of 3.82, 3.61, and $3.39 \mathrm{eV}$, respectively. Although the PBE band gaps are typically underestimated and do not take into account the exciton binding energies, the trend of the calculated band gaps is consistent with that of the exciton excitation energies, which are $3.21 \mathrm{eV}$ for (R) $\mathrm{ZnBr}_{3}(\mathrm{DMSO}), 3.11 \mathrm{eV}$ for (R) ${ }_{2} \mathrm{CdBr}_{4} \cdot \mathrm{DMSO}$, and $2.79 \mathrm{eV}$ for (R) $\mathrm{CdI}_{3}(\mathrm{DMSO})$. All three compounds show small dispersion for the electronic bands near the band gap, indicating that these bands are made up of highly localized electronic states. The band gaps of these compounds are slightly indirect. The valence band maximum (VBM) and the conduction band minimum (CBM) are located at the $\Gamma$ and $\mathrm{Y}$ points, respectively, for (R)$\mathrm{ZnBr}_{3}(\mathrm{DMSO})$, at the $\mathrm{N}$ and the $\Gamma$ points for $(\mathrm{R})_{2} \mathrm{CdBr}_{4}$. DMSO, and at the $\mathrm{Z}$ and the $\Gamma$ points for (R) $\mathrm{CdI}_{3}(\mathrm{DMSO})$. In luminescent $\mathrm{OD}$ hybrid $\mathrm{Sn}$ - and $\mathrm{Pb}$-based halides, the inorganic $\mathrm{Sn} / \mathrm{Pb}$ halide clusters are usually the luminescent centers because of their relatively small energy gaps of the inorganic substructures compared to those of organic molecules. ${ }^{23,26,62}$ The low energy gaps of the inorganic substructures in such cases are ensured by the relatively small electronegativity difference between $\mathrm{Sn} / \mathrm{Pb}$ and halogen elements, which results in valence bands being dominated by halogen orbitals and conduction bands being primarily made up of metal orbitals. In principle, the band alignment in hybrid halides can be altered by (1) combining pairs of metal and halogen elements with large electronegativity difference to accommodate the organic molecules' frontier orbitals or (2) by utilizing low-gap aromatic molecular cations. The hybrid metal halides studied in this work feature electropositive metals $\mathrm{Zn}$ and $\mathrm{Cd}^{36}$ and an aromatic organic cation, yielding unusual band alignments at the organic-inorganic interface. The DOS plots in Figure 8 show that (R) $\mathrm{ZnBr}_{3}(\mathrm{DMSO})$ exhibits the type I band alignment with its VBM and CBM derived from the bonding and the antibonding $\pi$ orbitals of the aromatic molecule cations, whereas $(\mathrm{R})_{2} \mathrm{CdBr}_{4} \cdot \mathrm{DMSO}$ and $(\mathrm{R}) \mathrm{CdI}_{3}(\mathrm{DMSO})$ display the type II band alignment with the VBM and the CBM containing $\pi$ orbitals of the organic cations and the metal $\mathrm{s}$ orbitals of the inorganic anions, respectively. It is thus expected that the optical emission from ( $\mathrm{R}) \mathrm{ZnBr}_{3}(\mathrm{DMSO})$ is due to the excitons localized on the organic molecular cations. Although the ground-state band structures of $(\mathrm{R})_{2} \mathrm{CdBr}_{4} \cdot \mathrm{DMSO}$ and (R) $\mathrm{CdI}_{3}$ (DMSO) show the type II band alignment, the lowest unoccupied molecular orbital of the molecular cation is close to the CBM, as shown in Figure 8d,f. The strong Coulomb binding could localize the exciton at the organic cation, in analogy to the case of $\left(\mathrm{Ph}_{4} \mathrm{P}\right)_{2} \mathrm{SbCl}_{5}$, in which the exciton is localized at the $\mathrm{SbCl}_{5}$ cluster despite the ground-state band structure showing the type II band alignment at the organicinorganic interface. ${ }^{23}$ The fast decay of the luminescence in the three hybrid metal halides, as shown in Figure 4 (9-21 ns), is consistent with the fast emission from the $\pi$-conjugated organic molecules (decay times ranging from a few nanoseconds to a few tens of nanoseconds), ${ }^{63}$ thus supporting the attribution of the exciton emission in these hybrid halides to the organic molecules. In comparison, an exciton that is localized at the inorganic metal halide cluster in hybrid metal halides usually has the lifetime on the order of microseconds. ${ }^{23,26,64}$ Figure 9 shows the hole and the electron (a) Hole

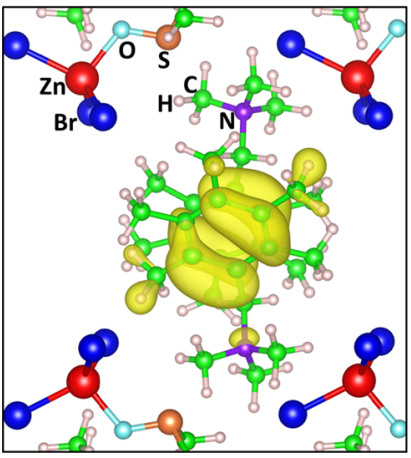

(b) Electron

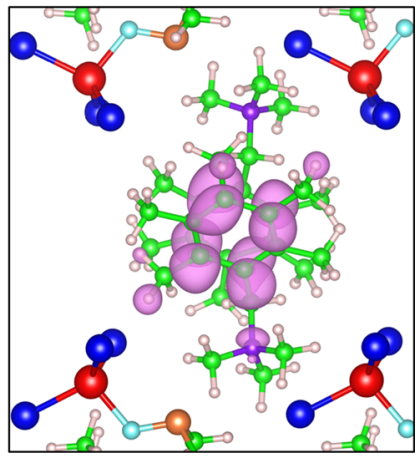

Figure 9. (a, b) Partial density contours of the (a) hole and the (b) electron in a relaxed exciton in ( $\mathrm{R}) \mathrm{ZnBr}_{3}(\mathrm{DMSO})$.

wavefunctions of an exciton in ( $\mathrm{R}) \mathrm{ZnBr}_{3}(\mathrm{DMSO})$, which is optimized by the PBE0 hybrid functional calculation. It can be seen that the exciton is indeed localized on the $\pi$ orbitals of the $\mathrm{C}_{6}$ ring in a molecular cation, which, thus, should act as a luminescent center.

\section{CONCLUSIONS}

In summary, we report the preparation, crystal and electronic structures, and optical properties of three new hybrid organicinorganic halides of group 12 metals. Because of the presence of the bulky organic $(\mathrm{R})^{+}$cation, all compounds form $\mathrm{OD}$ crystal structures featuring alternating layers of isolated inorganic anions based on metal tetrahedra and organic cations. The separation of the crystal structure into distinct inorganic and organic molecular units leads to flat bands near the band gap, indicative of the highly localized electronic states. Furthermore, the OD molecular structures allow for the localization of the excitons on either anionic or cationic molecular units, depending on their chemistries. Thus, on the basis of our computational work, the excitons are localized on the organic molecular cation in ( $\mathrm{R}) \mathrm{ZnBr}_{3}(\mathrm{DMSO})$, suggesting a rare example of light emission from the organic component of hybrid organic-inorganic materials. ${ }^{6,12,21,65}$ The computational results are supported by the PL measurements, including the measured fast decay of the luminescence (9-21 ns), which is consistent with the fast emission from the $\pi$-conjugated organic molecules.

The compounds exhibit broadband emission ranging from bluish-white to white to green light, depending on the choice of the halide and metal cations. The luminescence properties derive from the intricacies of their crystal and electronic structures (e.g., packing of the organic cations). Temperature dependence of PL measurements showed the emergence of additional peaks around $550 \mathrm{~nm}$ at lower temperatures, attributed to the organic salt emission. For $(\mathrm{R})_{2} \mathrm{CdBr}_{4}$. DMSO, an excitonic activation energy $E_{\mathrm{a}} \approx 50 \mathrm{meV}$ was estimated from the thermal dependence of the intensity of B1 
PL peak, showing a good agreement with Cd-based organicinorganic hybrid materials.

The OD crystal structures designed in this work demonstrate a luminescence efficiency with PLQY values of up to 3.07\% for the white light-emitting (R) $\mathrm{ZnBr}_{3}$ (DMSO), which also happens to be the most stable (thermally and in air) member of the family. The combinations of the organic cation and inorganic components used in this work are therefore responsible for the preparation of room-temperature luminescent materials that have comparable or better PLQY values to other $\mathrm{Pb}$ - and $\mathrm{Cd}$-based hybrid halides reported in the literature. Importantly, this work paves the way to band alignment engineering of organic and inorganic components in hybrid organic-inorganic halides to controllably create type I and type II band alignments and to fabricate materials where the emission originates from organic, inorganic, or both components. The fast emission from the hydrogen-rich organic cations, observed for the compounds prepared in this work, may enable the development of fast scintillators that are capable of detecting fast neutrons via proton recoil.

\section{EXPERIMENTAL METHODS}

Starting Materials. Chemicals utilized in this study were either used as purchased or synthesized from the starting materials listed: (i) zinc bromide, 99.999\%, Sigma; (ii) zinc iodide, 99.995\%, Alfa Aesar; (iii) cadmium bromide, 98\% Alfa Aesar; (iv) cadmium iodide, 99.999\%, Alfa Aesar; (v) dimethyl sulfoxide, ACS grade, Fisher; (vi) methanol, ACS reagent grade, Pharmco-Aaper. (vii) pentamethylbenzene, Aldrich; (viii) paraformaldehyde, 95\%, Aldrich; (ix) hydrobromic acid, 48\%, Sigma-Aldrich; (x) cetyltrimethyl ammonium bromide, Sigma; (xi) acetic acid, ACS reagent grade, 99.8\%, Sigma-Aldrich; (xii) o-phosphoric acid, ACS-certified, 85\%, Fisher; (xiii) methyl iodide, Aldrich; (xiv) trimethylamine hydrochloride, 98\%, Aldrich.

Syntheses of Hybrid Organic-Inorganic Compounds. For the syntheses of hybrid organic-inorganic halides of group 12 metals, various solvents including $N, N$-dimethylformamide (DMF), DMSO, and methanol were tried. Among these, DMSO was selected as the most suitable solvent because of the highest solubility of the precursor organic salts trimethyl(2,3,4,5,6-pentamethylbenzyl)ammonium halides $(\mathrm{R}) \mathrm{X}(\mathrm{X}=$ $\mathrm{Br}$ or I). Details of the syntheses and characterizations of the organic salts are described in the Supporting Information (see Figures S1-S4). It was determined that single crystals of target compounds can be grown in $20 \mathrm{~mL}$ drams at $65{ }^{\circ} \mathrm{C}$ by separately solvating $(\mathrm{R}) \mathrm{X}(\mathrm{X}=\mathrm{Br}$ or $\mathrm{I})$ in $2 \mathrm{~mL}$ of $\mathrm{DMSO}$ and $\mathrm{MX}_{2}(\mathrm{M}=\mathrm{Zn}$ or $\mathrm{Cd})$ in $1 \mathrm{~mL}$ of methanol and then mixing the stoichiometric 1:1 molar ratio solutions together.

Bromide-Based Compounds. (R) $\mathrm{ZnBr}_{3}$ (DMSO) crystals were grown through slow evaporation of their stoichiometric solutions, as described above. ( $\mathrm{R})_{2} \mathrm{CdBr}_{4} \cdot \mathrm{DMSO}$ was first obtained by reacting $(\mathrm{R}) \mathrm{Br}$ and $\mathrm{CdBr}_{2}$ in a nonstoichiometric 1:1 molar ratio. A subsequent stoichiometric reaction with 2:1 molar ratio of $(\mathrm{R}) \mathrm{Br} / \mathrm{CdBr}_{2}$ also afforded $(\mathrm{R})_{2} \mathrm{CdBr}_{4} \cdot \mathrm{DMSO}$. In all cases, colorless block crystals measuring up to $3 \mathrm{~mm}$ formed over a 3 week crystallization period.

lodide-Based Compound. (R) $\mathrm{CdI}_{3}$ (DMSO) crystals were grown through slow evaporation of their stoichiometric solutions as light-yellow blocks measuring up to $2 \mathrm{~mm}$ in size over a 3 week crystallization period. Syntheses of $\mathrm{Zn}$ analogues $(\mathrm{R}) \mathrm{ZnI}_{3}$ and $(\mathrm{R})_{2} \mathrm{ZnI}_{4}$ were tried in different loading ratios of DMF, DMSO, and methanol solutions but were proven unsuccessful.

Single-Crystal X-ray Diffraction. The X-ray intensity data for all compounds were collected on a Bruker Apex CCD diffractometer with a graphite monochromated Mo $\mathrm{K} \alpha(\lambda=$ $0.71073 \AA$ A) radiation. For room-temperature measurements $(298(2) \mathrm{K})$, crystals with good clarity were selected from their mother liquor, cut to size, covered with Super Glue, affixed to a goniometer head, and allowed to dry. For low-temperature measurements, crystals were selected from their mother liquor, placed in Dow Chemical vacuum grease, cut to size, and then cooled to $100(2) \mathrm{K}$. The crystal structures for all compounds were determined from a nonlinear least-squares fit. The data were corrected for absorption by the semi-empirical method based on equivalents, and the structures were solved by direct methods using the SHELXTL program and refined by fullmatrix least squares on $F^{2}$ by the use of all reflections. ${ }^{66,67}$ All nonhydrogen atoms were refined with anisotropic displacement parameters, all occupancies were refined within two standard deviations, and all hydrogen atom positions were determined by geometry. Single-crystal data collection and refinement parameters are summarized in Table 1 and Table S1. Atomic coordinates, equivalent isotropic displacement parameters, and selected interatomic distances and bond angles can be found in Tables S2 and S3. Full details of the crystal structures are summarized in the CIF (Crystallographic Information File) files that have been deposited in the Cambridge Crystallographic Data Centre (CCDC) database and can be found under deposition numbers 1840612 and 1840614-1840618.

Powder X-ray Diffraction. For PXRD measurements, solution-processed samples were dried overnight under vacuum and then ground into powdered forms. PXRD measurements were carried out on a Rigaku MiniFlex600 system equipped with a $\mathrm{D} /$ teX detector using a Ni-filtered $\mathrm{Cu}$ $\mathrm{K} \alpha$ radiation source. Typical PXRD scans were performed in the $5^{\circ}-90^{\circ}(2 \theta)$ range, with a step size of $0.02^{\circ}$ to determine phase identity and purity. Data analysis was performed using the Rigaku's PDXL2 software package. The baseline originating from the glass slides used to collect data was corrected using the embedded tool in the PDXL2 software, and the data were fitted using the decomposition method (also known as Pawley fitting) embedded in the PDXL2 software package.

Energy-Dispersive X-ray (EDX) Spectroscopy Measurements. EDX measurements were conducted to confirm the heavy element compositions of the samples (metal/ halogen ratios) using a Zeiss Neon EsB equipped with an Oxford Instruments EDX system.

Optical Measurements. Room-temperature PLE, PL, and PLQY measurements were performed on a HORIBA Jobin Yvon Fluorolog-3 spectrofluorometer using a xenon lamp and Quanta- $\varphi$ integrating sphere using the two-curve method in a varied range from 280 to $860 \mathrm{~nm}$. UV-Vis diffuse reflectance was measured to study the optical absorption properties of the compounds. Measurements were performed on polycrystalline powder samples using a PerkinElmer Lambda $750 \mathrm{UV} / \mathrm{Vis} /$ NIR spectrometer equipped with a $100 \mathrm{~mm}$ Spectralon InGaAs Integrating Sphere attachment over a 250-1100 nm range. TRPL was measured on a HORIBA Jobin Yvon Fluorolog-3 spectrofluorometer using a time-correlated single photon counting module. HORIBA Jobin Yvon NanoLEDs (pulsed light-emitting diodes) were used as the excitation source. The 
duration of the light pulse was shorter than 2 ns. Temperature dependence PL spectra were measured on single-crystal samples using a double monochromator U1000 equipped with a photomultiplier. The excitation wavelength was the 325 $\mathrm{nm}(3.815 \mathrm{eV})$ line of a Spectra Physics Beamlock 2085 argon laser. The samples were placed in a helium bath cryostat, and the measurements were performed between 2 and $300 \mathrm{~K}$. Room-temperature solid-state mid-IR measurements were performed on a Bruker Tensor27 IR over the range of 400$4000 \mathrm{~cm}^{-1}$ on solid samples that were ground and then pressed into a matrix of $\mathrm{KBr}$. The IR measurements show the presence of well-defined vibration mode peaks similar to that of their organic salts, as shown in Figure S6, which confirms the good quality of the compounds.

First-Principle Calculations. All calculations were based on DFT implemented in the VASP code. ${ }^{68}$ The interaction between ions and electrons was described by the projector augmented wave method. ${ }^{69}$ The kinetic energy cutoff of 400 $\mathrm{eV}$ for the plane-wave basis was used for all calculations. Experimental lattice parameters were used while the atomic positions were fully relaxed until the residual forces were less than $0.02 \mathrm{eV} / \AA$. Electronic band structures and DOSs were calculated using the Perdew-Burke-Ernzerhof (PBE) exchange-correlation functional, ${ }^{70}$ whereas excitons were treated by using the more advanced hybrid PBE0 functional, ${ }^{62}$ which has $25 \%$ nonlocal Fock exchange. Previous PBE0 calculations have provided accurate results on exciton properties in hybrid organic-inorganic halide perovskites. ${ }^{23,26,71}$

\section{ASSOCIATED CONTENT}

\section{S Supporting Information}

The Supporting Information is available free of charge on the ACS Publications website at DOI: 10.1021/acsomega.8b02883.

Syntheses of the organic precursor salts, their NMR spectra, the results of stability studies, infrared spectra, the results of low-temperature crystallography experiments, tables with atomic coordinates, and interatomic distances and bond angles (PDF)

\section{AUTHOR INFORMATION}

\section{Corresponding Authors}

*E-mail: mhdu@ornl.gov (M.-H.D.).

*E-mail: saparov@ou.edu (B.S.).

\section{ORCID $\odot$}

Aymen Yangui: 0000-0002-6695-972X

Shiyou Chen: 0000-0002-4039-8549

Kamel Boukheddaden: 0000-0003-0464-1609

Mao-Hua Du: 0000-0001-8796-167X

Bayrammurad Saparov: 0000-0003-0190-9585

\section{Notes}

The authors declare no competing financial interest.

\section{ACKNOWLEDGMENTS}

Single-crystal X-ray diffraction measurements were collected on instruments purchased using NSF grants CHE-1726630 and CHE-0130835. Additional financial support for this work was provided by the University of Oklahoma start-up funds and by a grant from the Research Council of the University of Oklahoma Norman Campus. M.-H.D. was supported by the U.S. Department of Energy, Office of Science, Basic Energy
Sciences, Materials Sciences and Engineering Division. H.S. was supported by the National Natural Science Foundation of China (NSFC) under grant no. 11604007 and the start-up funding at Beihang University. D.H. and S.C. were supported by the State Scholarship Fund in China, NSFC under grant nos. 61574059 and 61722402, and CC of ECNU. The University of Versailles and CNRS-France are also acknowledged.

\section{REFERENCES}

(1) Saparov, B.; Mitzi, D. B. Organic-Inorganic Perovskites: Structural Versatility for Functional Materials Design. Chem. Rev. 2016, 116, 4558-4596.

(2) Mitzi, D. B. Templating and structural engineering in organicinorganic perovskites. J. Chem. Soc., Dalton Trans. 2001, 0, 1-12.

(3) Mitzi, D. B. Synthesis, structure, and properties of organicinorganic perovskites and related materials. Prog. Inorg. Chem. 2007, $48,1-121$.

(4) Deschler, F.; Price, M.; Pathak, S.; Klintberg, L. E.; Jarausch, D. D.; Higler, R.; Hüttner, S.; Leijtens, T.; Stranks, S. D.; Snaith, H. J.; Atatüre, M.; Phillips, R. T.; Friend, R. H. High Photoluminescence Efficiency and Optically Pumped Lasing in Solution-Processed Mixed Halide Perovskite Semiconductors. J. Phys. Chem. Lett. 2014, 5, $1421-1426$.

(5) Xing, G.; Mathews, N.; Lim, S. S.; Yantara, N.; Liu, X.; Sabba, D.; Grätzel, M.; Mhaisalkar, S.; Sum, T. C. Low-Temperature Solution-Processed Wavelength-Tunable Perovskites for Lasing. Nat. Mater. 2014, 13, 476-480.

(6) Manser, J. S.; Christians, J. A.; Kamat, P. V. Intriguing Optoelectronic Properties of Metal Halide Perovskites. Chem. Rev. 2016, 116, 12956-13008.

(7) Yang, W. S.; Park, B.-W.; Jung, E. H.; Jeon, N. J.; Kim, Y. C.; Lee, D. U.; Shin, S. S.; Seo, J.; Kim, E. K.; Noh, J. H.; Seok, S. I. Iodide management in formamidinium-lead-halide-based perovskite layers for efficient solar cells. Science 2017, 356, 1376-1379.

(8) Gong, X.; Voznyy, O.; Jain, A.; Liu, W.; Sabatini, R.; Piontkowski, Z.; Walters, G.; Bappi, G.; Nokhrin, S.; Bushuyev, O.; Yuan, M.; Comin, R.; McCamant, D.; Kelley, S. O.; Sargent, E. H. Electron-phonon interaction in efficient perovskite blue emitters. Nat. Mater. 2018, 17, 550-556.

(9) Comin, R.; Walters, G.; Thibau, E. S.; Voznyy, O.; Lu, Z.-H.; Sargent, E. H. Structural, optical, and electronic studies of widebandgap lead halide perovskites. J. Mater. Chem. C 2015, 3, 88398843.

(10) Dohner, E. R.; Hoke, E. T.; Karunadasa, H. I. Self-Assembly of Broadband White-Light Emitters. J. Am. Chem. Soc. 2014, 136, 17181721.

(11) Dohner, E. R.; Jaffe, A.; Bradshaw, L. R.; Karunadasa, H. I. Intrinsic White-Light Emission from Layered Hybrid Perovskites. J. Am. Chem. Soc. 2014, 136, 13154-13157.

(12) Yangui, A.; Garrot, D.; Lauret, J. S.; Lusson, A.; Bouchez, G.; Deleporte, E.; Pillet, S.; Bendeif, E. E.; Castro, M.; Triki, S.; Abid, Y.; Boukheddaden, K. Optical Investigation of Broadband White-Light Emission in Self-Assembled Organic-Inorganic Perovskite $\left(\mathrm{C}_{6} \mathrm{H}_{11} \mathrm{NH}_{3}\right)_{2} \mathrm{PbBr}_{4}$. J. Phys. Chem. C 2015, 119, 23638-23647.

(13) Wu, Z.; Ji, C.; Sun, Z.; Wang, S.; Zhao, S.; Zhang, W.; Li, L.; Luo, J. Broadband white-light emission with a high color rendering index in a two-dimensional organic-inorganic hybrid perovskite. $J$. Mater. Chem. C 2018, 6, 1171-1175.

(14) Sutherland, B. R.; Sargent, E. H. Perovskite photonic sources. Nat. Photonics 2016, 10, 295-302.

(15) Peng, Y.; Yao, Y.; Li, L.; Wu, Z.; Wang, S.; Luo, J. White-light emission in a chiral one-dimensional organic-inorganic hybrid perovskite. J. Mater. Chem. C 2018, 6, 6033-6037.

(16) Wang, G.-E.; Xu, G.; Wang, M.-S.; Cai, L.-Z.; Li, W.-H.; Guo, G.-C. Semiconductive 3-D haloplumbate framework hybrids with high color rendering index white-light emission. Chem. Sci. 2015, 6, 72227226. 
(17) Lou, Y.; Fang, M.; Chen, J.; Zhao, Y. Formation of highly luminescent cesium bismuth halide perovskite quantum dots tuned by anion exchange. Chem. Commun. 2018, 54, 3779-3782.

(18) Lou, Y.; Niu, Y.; Yang, D.; Xu, Q.; Hu, Y.; Shen, Y.; Ming, J.; Chen, J.; Zhang, L.; Zhao, Y. Rod-shaped thiocyanate-induced abnormal band gap broadening in $\mathrm{SCN}-$ doped $\mathrm{CsPbBr}_{3}$ perovskite nanocrystals. Nano Res. 2018, 11, 2715-2723.

(19) Roccanova, R.; Ming, W.; Whiteside, V. R.; McGuire, M. A.; Sellers, I. R.; Du, M. H.; Saparov, B. Synthesis, Crystal and Electronic Structures, and Optical Properties of $\left(\mathrm{CH}_{3} \mathrm{NH}_{3}\right)_{2} \mathrm{CdX}_{4}(\mathrm{X}=\mathrm{Cl}, \mathrm{Br}$, I). Inorg. Chem. 2017, 56, 13878-13888.

(20) Yangui, A.; Pillet, S.; Bendeif, E.-E.; Lusson, A.; Triki, S.; Abid, Y.; Boukheddaden, K. Broadband Emission in a New TwoDimensional Cd-Based Hybrid Perovskite. ACS Photonics 2018, 5, 1599-1611.

(21) Smith, M. D.; Karunadasa, H. I. White-Light Emission from Layered Halide Perovskites. Acc. Chem. Res. 2018, 51, 619-627.

(22) Lin, H.; Zhou, C.; Tian, Y.; Siegrist, T.; Ma, B. LowDimensional Organometal Halide Perovskites. ACS Energy Lett. 2018, 3, 54-62.

(23) Zhou, C.; Worku, M.; Neu, J.; Lin, H.; Tian, Y.; Lee, S.; Zhou, Y.; Han, D.; Chen, S.; Hao, A.; Djurovich, P. I.; Siegrist, T.; Du, M.H.; Ma, B. Facile Preparation of Light Emitting Organic Metal Halide Crystals with Near-Unity Quantum Efficiency. Chem. Mater. 2018, 30, 2374-2378.

(24) Zhou, C.; Tian, Y.; Wang, M.; Rose, A.; Besara, T.; Doyle, N. K.; Yuan, Z.; Wang, J. C.; Clark, R.; Hu, Y.; Siegrist, T.; Lin, S.; Ma, B. Low-Dimensional Organic Tin Bromide Perovskites and Their Photoinduced Structural Transformation. Angew. Chem. Int. Ed. 2017, 56, 9018-9022.

(25) Liu, W.; Zhu, K.; Teat, S. J.; Dey, G.; Shen, Z.; Wang, L.; O'Carroll, D. M.; Li, J. All-in-One: Achieving Robust, Strongly Luminescent and Highly Dispersible Hybrid Materials by Combining Ionic and Coordinate Bonds in Molecular Crystals. J. Am. Chem. Soc. 2017, 139, 9281-9290.

(26) Zhou, C.; Lin, H.; Shi, H.; Tian, Y.; Pak, C.; Shatruk, M.; Zhou, Y.; Djurovich, P.; Du, M.-H.; Ma, B. A Zero-Dimensional Organic Seesaw-Shaped Tin Bromide with Highly Efficient Strongly StokesShifted Deep-Red Emission. Angew. Chem. Int. Ed. 2018, 57, 10211024.

(27) Nhalil, H.; Whiteside, V. R.; Sellers, I. R.; Ming, W.; Du, M.-H.; Saparov, B. Synthesis, crystal and electronic structures and optical properties of $(\mathrm{HIm})_{2} \mathrm{Hg}_{3} \mathrm{Cl}_{8}$ and $(\mathrm{HIm}) \mathrm{HgI}_{3}(\mathrm{HIm}=$ imidazolium $) . \mathrm{J}$. Solid State Chem. 2018, 258, 551-558.

(28) Rademeyer, M.; Tsouris, C.; Billing, D. G.; Lemmerer, A.; Charmant, J. Robust motifs in 2-phenylethylammonium and related tetrahalometallates. CrystEngComm 2011, 13, 3485-3497.

(29) Gillon, A. L.; Lewis, G. R.; Orpen, A. G.; Rotter, S.; Starbuck, J.; Wang, X.-M.; Rodríguez-Martín, Y.; Ruiz-Pérez, C. Organicinorganic hybrid solids: control of perhalometallate solid state structures. J. Chem. Soc., Dalton Trans. 2000, 0, 3897-3905.

(30) Era, M.; Miyake, K.; Yoshida, Y.; Yase, K. Orientation of Azobenzene Chromophore Incorporated into Metal Halide-Based Layered Perovskite having Organic-Inorganic Superlattice Structure. Thin Solid Films 2001, 393, 24-27.

(31) Tieke, B.; Chapuis, G. Solid State Polymerization of Butadienes in Layer Structures. Mol. Cryst. Liq. Cryst. 1986, 137, 101-116.

(32) Kantor, S. W.; Hauser, C. R. Rearrangements of Benzyltrimethylammonium Ion and Related Quaternary Ammonium Ions by Sodium Amide Involving Migration into the Ring. J. Am. Chem. Soc. 1951, 73, 4122-4131.

(33) Shannon, R. D. Revised effective ionic radii and systematic studies of interatomic distances in halides and chalcogenides. Acta Cryst. A 1976, 32, 751-767.

(34) Villars, P. C.; Cenzual, K. Pearson's Crystal Data: Crystal Structure Database for Inorganic Compounds [DVD]; ASM International: Materials Park, OH, 2016/2017.

(35) Aristidou, N.; Sanchez-Molina, I.; Chotchuangchutchaval, T.; Brown, M.; Martinez, L.; Rath, T.; Haque, S. A. The Role of Oxygen in the Degradation of Methylammonium Lead Trihalide Perovskite Photoactive Layers. Angew. Chem. Int. Ed. 2015, 54, 8208-8212.

(36) Dastidar, S.; Egger, D. A.; Tan, L. Z.; Cromer, S. B.; Dillon, A. D.; Liu, S.; Kronik, L.; Rappe, A. M.; Fafarman, A. T. High Chloride Doping Levels Stabilize the Perovskite Phase of Cesium Lead Iodide. Nano Lett. 2016, 16, 3563-3570.

(37) Dammak, T.; Abid, Y. Quasi-white light emission involving Förster resonance energy transfer in a new organic inorganic tin chloride based material (AMPS) $\left[\mathrm{SnCl}_{6}\right] \mathrm{H}_{2} \mathrm{O}$. Opt. Mater. 2017, 66, 302-307.

(38) Mao, L.; Wu, Y.; Stoumpos, C. C.; Wasielewski, M. R.; Kanatzidis, M. G. White-Light Emission and Structural Distortion in New Corrugated Two-Dimensional Lead Bromide Perovskites. J. Am. Chem. Soc. 2017, 139, 5210-5215.

(39) Mao, L.; Wu, Y.; Stoumpos, C. C.; Traore, B.; Katan, C.; Even, J.; Wasielewski, M. R.; Kanatzidis, M. G. Tunable White-Light Emission in Single-Cation-Templated Three-Layered 2D Perovskites $\left(\mathrm{CH}_{3} \mathrm{CH}_{2} \mathrm{NH}_{3}\right)_{4} \mathrm{~Pb}_{3} \mathrm{Br}_{10-x} \mathrm{Cl}_{x}$. J. Am. Chem. Soc. 2017, 139, 1195611963.

(40) Barkaoui, H.; Abid, H.; Yangui, A.; Triki, S.; Boukheddaden, K.; Abid, Y. Yellowish White-Light Emission Involving Resonant Energy Transfer in a New One-Dimensional Hybrid Material: $\left(\mathrm{C}_{9} \mathrm{H}_{10} \mathrm{~N}_{2}\right)$ $\mathrm{PbCl}_{4}$. J. Phys. Chem. C 2018, 122, 24253-24261.

(41) Hernández-Andrés, J.; Lee, R. L.; Romero, J. Calculating correlated color temperatures across the entire gamut of daylight and skylight chromaticities. Appl. Opt. 1999, 38, 5703-5709.

(42) Nakagawa, H.; Hayashi, K.; Matsumoto, H. Luminescence of $\mathrm{CdCl}_{2}-\mathrm{CdBr}_{2}$ Solid Solutions. J. Phys. Soc. Jpn. 1977, 43, 1655-1663.

(43) Yangui, A.; Pillet, S.; Lusson, A.; Bendeif, E.-E.; Triki, S.; Abid, Y.; Boukheddaden, K. Control of the White-Light Emission in the Mixed Two-Dimensional Hybrid Perovskites $\left(\mathrm{C}_{6} \mathrm{H}_{11} \mathrm{NH}_{3}\right)_{2}\left[\mathrm{PbBr}_{4-\mathrm{x}} \mathrm{I}_{\mathrm{x}}\right]$. J. Alloys Compd. 2017, 699, 1122-1133.

(44) Saidaminov, M. I.; Almutlaq, J.; Sarmah, S.; Dursun, I.; Zhumekenov, A. A.; Begum, R.; Pan, J.; Cho, N.; Mohammed, O. F.; Bakr, O. M. Pure $\mathrm{Cs}_{4} \mathrm{PbBr}_{6}$ : Highly Luminescent Zero-Dimensional Perovskite Solids. ACS Energy Lett. 2016, 1, 840-845.

(45) Zhang, Y.; Saidaminov, M. I.; Dursun, I.; Yang, H.; Murali, B.; Alarousu, E.; Yengel, E.; Alshankiti, B. A.; Bakr, O. M.; Mohammed, O. F. Zero-Dimensional $\mathrm{Cs}_{4} \mathrm{PbBr}_{6}$ Perovskite Nanocrystals. J. Phys. Chem. Lett. 2017, 8, 961-965.

(46) Dammak, T.; Koubaa, M.; Boukheddaden, K.; Bougzhala, H.; Mlayah, A.; Abid, Y. Two-Dimensional Excitons and Photoluminescence Properties of the Organic/Inorganic (4$\left.\mathrm{FC}_{6} \mathrm{H}_{4} \mathrm{C}_{2} \mathrm{H}_{4} \mathrm{NH}_{3}\right)_{2}\left[\mathrm{PbI}_{4}\right]$ Nanomaterial. J. Phys. Chem. C 2009, 113, 19305-19309.

(47) Allred, A. L. Electronegativity values from thermochemical data. J. Inorg. Nucl. Chem. 1961, 17, 215-221.

(48) Hayashi, T.; Ohata, T.; Koshino, S. Indirect exciton luminescense and Raman scattering in $\mathrm{CdI}_{2}$. Solid State Commun. 1981, 38, 845-847.

(49) Ohnishi, A.; Kitaura, M.; Nakagawa, H. Determination of Optical Gain of Self-Trapped Exciton Luminescence in $\mathrm{CdI}_{2}$. J. Phys. Soc. Jpn. 1994, 63, 4648-4654.

(50) Kawabata, S.; Kitaura, M.; Nakagawa, H. Life-time resolved emission spectra in $\mathrm{CdCl}_{2}$ crystals. Phys. Status Solidi C 2005, 2, 5356.

(51) Kitaura, M.; Nakagawa, H.; Fukui, K.; Fujita, M.; Miyanaga, T.; Watanabe, M. Decay Time Studies on UV-Luminescence in $\mathrm{CdBr}_{2}$. $\mathrm{CdCl}_{2}$ Mixed Crystals. J. Electron Spectrosc. Relat. Phenom. 1996, 79, $175-178$.

(52) Thirumal, K.; Chong, W. K.; Xie, W.; Ganguly, R.; Muduli, S. K.; Sherburne, M.; Asta, M.; Mhaisalkar, S.; Sum, T. C.; Soo, H. S.; Mathews, N. Morphology-Independent Stable White-Light Emission from Self-Assembled Two-Dimensional Perovskites Driven by Strong Exciton-Phonon Coupling to the Organic Framework. Chem. Mater. 2017, 29, 3947-3953.

(53) Neogi, I.; Bruno, A.; Bahulayan, D.; Goh, T. W.; Ghosh, B.; Ganguly, R.; Cortecchia, D.; Sum, T. C.; Soci, C.; Mathews, N.; Mhaisalkar, S. G. Broadband-Emitting 2D Hybrid Organic-Inorganic 
Perovskite Based on Cyclohexane-bis(methylamonium) Cation. ChemSusChem 2017, 10, 3765-3772.

(54) Fujisawa, J.-i.; Ishihara, T. Excitons and biexcitons bound to a positive ion in a bismuth-doped inorganic-organic layered lead iodide semiconductor. Phys. Rev. B 2004, 70, 205330.

(55) Hong, X.; Ishihara, T.; Nurmikko, A. V. Dielectric Confinement Effect on Excitons in $\mathrm{PbI}_{4}$-Based Layered Semiconductors. Phys. Rev. B: Condens. Matter 1992, 45, 6961-6964.

(56) Yangui, A.; Pillet, S.; Mlayah, A.; Lusson, A.; Bouchez, G.; Triki, S.; Abid, Y.; Boukheddaden, K. Structural phase transition causing anomalous photoluminescence behavior in perovskite $\left(\mathrm{C}_{6} \mathrm{H}_{11} \mathrm{NH}_{3}\right)_{2}\left[\mathrm{PbI}_{4}\right]$. J. Chem. Phys. 2015, 143, 224201.

(57) Yangui, A.; Pillet, S.; Garrot, D.; Triki, S.; Abid, Y.; Boukheddaden, K. Evidence and detailed study of a second-order phase transition in the $\left(\mathrm{C}_{6} \mathrm{H}_{11} \mathrm{NH}_{3}\right)_{2}\left[\mathrm{PbI}_{4}\right]$ organic-inorganic hybrid material. J. Appl. Phys. 2015, 117, 115503.

(58) Yangui, A.; Sy, M.; Li, L.; Abid, Y.; Naumov, P.; Boukheddaden, K. Rapid and robust spatiotemporal dynamics of the first-order phase transition in crystals of the organic-inorganic perovskite $\left(\mathrm{C}_{12} \mathrm{H}_{25} \mathrm{NH}_{3}\right)_{2} \mathrm{PbI}_{4}$. Sci. Rep. 2015, 5, 16634.

(59) Lee, J.; Koteles, E. S.; Vassell, M. O. Luminescence linewidths of excitons in GaAs quantum wells below 150 K. Phys. Rev. B 1986, $33,5512$.

(60) Hehlen, M. P.; Kuditcher, A.; Rand, S. C.; Tischler, M. A. Electron-phonon interactions in $\mathrm{CsCdBr}_{3}: \mathrm{Yb}^{3+}$. J. Chem. Phys. 1997, $107,4886$.

(61) Lockwood, D. J. Lattice vibrations of $\mathrm{CdCl}_{2}, \mathrm{CdBr}_{2}, \mathrm{MnCl}_{2}$, and $\mathrm{CoCl}_{2}$ : Infrared and Raman spectra. J. Opt. Soc. Am. 1973, 63, 374-382.

(62) Perdew, J. P.; Ernzerhof, M.; Burke, K. Rationale for mixing exact exchange with density functional approximations. J. Chem. Phys. 1996, 105, 9982-9985.

(63) Birks, J. B. Organic Crystal Scintillators. In The Theory and Practice of Scintillation Counting; Birks, J. B., Ed.; Pergamon: London, 1964; pp 235-268, DOI: 10.1016/B978-0-08-010472-0.50012-4.

(64) Birks, J. B. The Theory and Practice of Scintillation Counting: International Series of Monographs in Electronics and Instrumentation; Elsevier: 2013; Vol. 27.

(65) Cortecchia, D.; Yin, J.; Bruno, A.; Lo, S.-Z. A.; Gurzadyan, G. G.; Mhaisalkar, S.; Brédas, J.-L.; Soci, C. Polaron Self-Localization in White-light Emitting Hybrid Perovskites. J. Mater. Chem. C 2017, 5, 2771-2780.

(66) Linden, A. Chemistry and structure in Acta Crystallographica Section C. Acta Cryst. C 2015, 71, 1-2.

(67) Sheldrick, G. M. SHELXT - Integrated space-group and crystal-structure determination. Acta Cryst. A 2015, 71, 3-8.

(68) Kresse, G.; Furthmüller, J. Efficiency of ab-initio total energy calculations for metals and semiconductors using a plane-wave basis set. Comput. Mater. Sci. 1996, 6, 15-50.

(69) Kresse, G.; Furthmüller, J. Efficient iterative schemes for ab initio total-energy calculations using a plane-wave basis set. Phys. Rev. B 1996, 54, 11169-11186.

(70) Perdew, J. P.; Burke, K.; Ernzerhof, M. Generalized Gradient Approximation Made Simple. Phys. Rev. Lett. 1996, 77, 3865-3868.

(71) Han, D.; Shi, H.; Ming, W.; Zhou, C.; Ma, B.; Saparov, B.; Ma, Y.-Z.; Chen, S.; Du, M.-H. Unraveling luminescence mechanisms in zero-dimensional halide perovskites. J. Mater. Chem. C 2018, 6, 63986405. 